Propul si ve Perfor nance and Heat i ng Envi ronment of Rot at ing Det onat i on Engi ne wi th Vari ous Nozzl es

\begin{tabular}{|l|l|}
\hline 著者 & $\begin{array}{l}\text { GOTO Kei suke, N SH MRA Junpei, KAWASAK } \\
\text { Aki ra, MATSUOKA Ken, KASAHARA Ji ro, MATSUO } \\
\text { Aki ko, FUNAK I kkoh, NAKATA Dai suke, UCH UM } \\
\text { Nasahar u, H GASH NO Kazuyuki }\end{array}$ \\
\hline $\begin{array}{l}\text { j our nal or } \\
\text { publ i cat i on t i t e }\end{array}$ & Journal of Propul si on and Power \\
\hline vol une & 35 \\
\hline number & 1 \\
\hline page r ange & $213-223$ \\
\hline year & $2019-01$ \\
\hline URL & ht t p: //hdl . handl e. net /10258/00009917 \\
\hline
\end{tabular}




\title{
Propulsive Performance and Heating Environment of Rotating Detonation Engine with Various Nozzles
}

\author{
Keisuke Goto,, Junpei Nishimura, ${ }^{*}$ Akira Kawasaki, ${ }^{\dagger}$ Ken Matsuoka, ${ }^{\ddagger}$ and Jiro Kasahara ${ }^{\S}$ - \\ Nagoya University, Nagoya 464-8603, Japan \\ Akiko Matsuo \\ Keio University, Yokohama 223-8522, Japan \\ Ikkoh Funaki** \\ Japan Aerospace Exploration Agency, Sagamihara 252-5210, Japan \\ and \\ Daisuke Nakata, \\ Muroran Institute of Technology, Muroran, Hokkai-do 050-8585, Japan
}

DOI: $\underline{10.2514 / 1 . B 37196}$

\begin{abstract}
Geometric throats are commonly applied to rocket combustors to increase pressure and specific impulse. This paper presents the results from thrust measurements of an ethylene/gas-oxygen rotating detonation engine with various throat geometries in a vacuum chamber to simulate varied backpressure conditions in a range of 1.1-104 kPa. For the throatless case, the detonation channel area was regarded to be equivalent the throat area, and three throat-contraction ratios were tested: $1,2.5$, and 8 . Results revealed that combustor pressure was approximately proportional to equivalent throat mass flux for all test cases. Specific impulse was measured for a wide range of pressure ratios, defined as the ratio of the combustor pressure to the backpressure in the vacuum chamber. The rotating detonation engine could achieve almost the same level of optimum specific impulse for each backpressure, whether or not flow was squeezed by a geometric throat. In addition, heat-flux measurements using heat-resistant material are summarized. Temporal and spatially averaged heat flux in the engine were roughly proportional to channel mass flux. Heat-resistant material wall compatibility with two injector shapes of doublet and triplet injection is also discussed.
\end{abstract}

\section{Nomenclature}

$A=$ flow cross-sectional area

$A_{s}=$ total axial surface area of combustion chamber from the bottom to nozzle tip

$a=$ thermal diffusivity

$C=$ heat capacity

$C_{d} \quad=$ mass flow coefficient

$c_{1}=$ constant

$c^{*} \quad=$ characteristic exhaust velocity

$d_{\text {ori }}=$ orifice diameter

$F=$ thrust

$g \quad=$ gravity acceleration

$h=$ heat transfer coefficient

$I_{\mathrm{sp}} \quad=$ specific impulse

$k=$ thermal conductivity

Presented as Paper 2018 at the SciTech 2018, 56th AIAA Aerospace Science Meeting, Kissimmee, Florida, 8-12 January 2018; received 4 May 2018; revision received 27 July 2018; accepted for publication 6 August 2018; published online XX epubMonth XXXX. Copyright (c) 2018 by Nagoya University. Published by the American Institute of Aeronautics and Astronautics, Inc., with permission. All requests for copying and permission to reprint should be submitted to CCC at www.copyright.com; employ the ISSN 0748-4658 (print) or 1533-3876 (online) to initiate your request. See also AIAA Rights and Permissions www.aiaa.org/randp.

* Graduate Student, Department of Aerospace Engineering, Aichi.

${ }^{\dagger}$ Assistant Professor, Department of Aerospace Engineering, Aichi. Member AIAA.

${ }^{\ddagger}$ Associate Professor, Department of Aerospace Engineering, Aichi. Member AIAA.

§Professor, Department of Aerospace Engineering, Aichi. Associate Fellow AIAA.

TProfessor, Department of Mechanical Engineering, Kanagawa. Senior Member AIAA.

**Associate Professor, Institute of Space and Astronautical Science, Kanagawa. Senior Member AIAA.

${ }^{\dagger}$ Assistant Professor, Aerospace Plane Research Center, Hokkai-do. Member AIAA.

靬Professor, Aerospace Plane Research Center, Hokkai-do. Member AIAA.

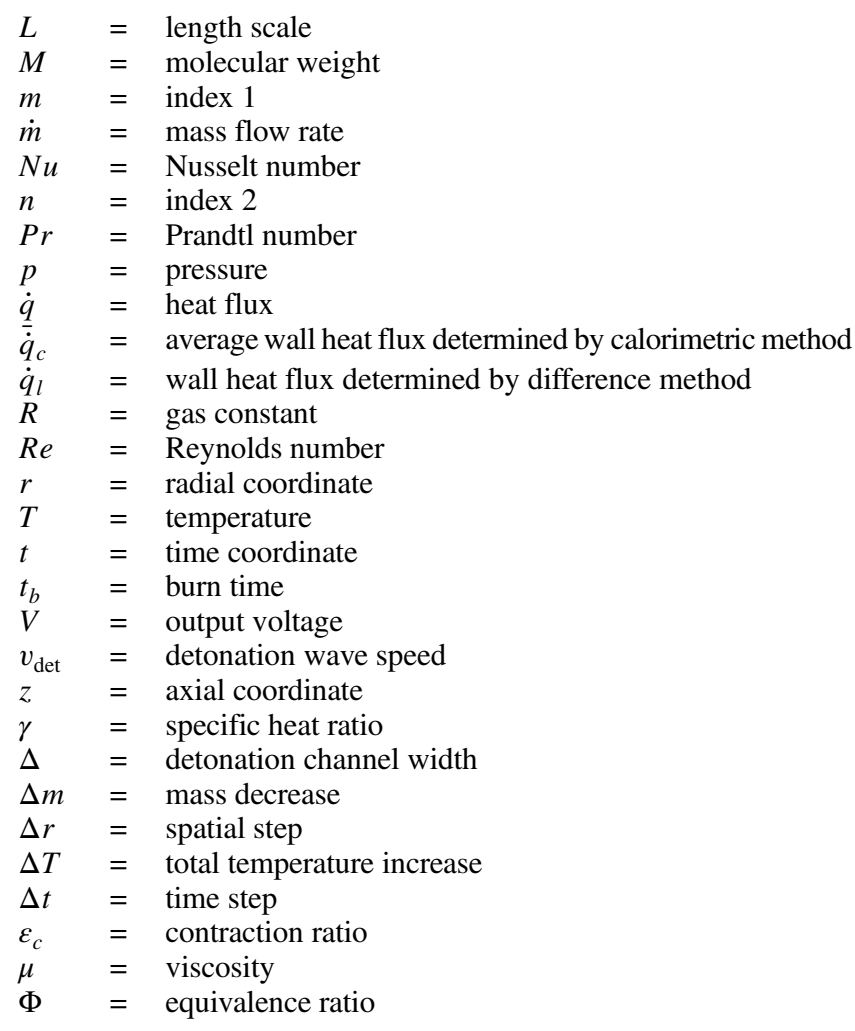

Subscripts

$a=$ adiabatic value

avg $=$ average value

$b=$ back value

$c=$ combustion chamber value

cc $=$ carbon - carbon composite value 
ch $=$ detonation channel value

cs $=$ material contact surface value

$\mathrm{cu}=$ copper value

$e \quad=$ exit value

$f \quad=$ fuel value

$i=$ ideal value

in $=$ inner value

inj $=$ total injector value

$j=\operatorname{index} 3$

$n=$ index 4

$o=$ stagnation value

op $=$ outer peripheral value

ope $=$ operational duration

opt $=$ optimum value

out $=$ outer value

ox $=$ oxidizer value

ple $=$ plenum value

tank $=$ tank value

th $=$ equivalent throat value

$w \quad=$ wall

$z=$ axial coordinate

\section{Introduction}

G EOMETRIC throats are common elements of rocket combustors, used to increase chamber pressure, thrust, and specific impulse. Detonation-driven systems are promising candidates to replace deflagration in aerospace propulsion systems because of their high thermal efficiency and short combustor length to complete the combustion [1-5]. Kailasanath [1,2], Wolanski [3], and Li et al. [4] widely reviewed applications and presented research developments in the area of detonative propulsion. System-level studies of a pulse detonation rocket conducted by Kasahara et al. [6] and Matsuoka et al. [7] validated detonative propulsion system performance with a sliding test [6] and vertical-flight test [7]. Compared to a pulse detonation engine (PDE), a rotating detonation engine (RDE) uses one or more detonation waves that continuously circle around its annular chamber to generate thrust. Kailasanath [1], Wolanski [3], and Lu and Braun [5] summarized the RDE's concept, characteristics, and applications as well as the challenges to practical implementation in their review papers. The important advantage of RDEs is an increase in specific impulse beyond existing rocket combustors. Frolov et al. [8] experimentally proved that the specific impulse of RDE was $6-7 \%$ higher than that in continuous combustion mode. The combination of high flame speed, on the order of kilometers per second, with continuous propellant flow rates can result in high thrust density, thrust-to-weight ratio, and volumetric efficiency $[3,5]$. In particular, the application of RDE as a spacecraft and rocket main thruster could enable smaller and more powerful propulsion systems.

To design a combustor that can sustain rotating detonations, the relation between geometric parameters and the structure of detonation waves was studied [9-11]. Bykovskii et al. [9] summarized the governing parameters of $\overline{\mathrm{R}} \overline{\mathrm{DE}}$ operating conditions and clarified that optimum geometric conditions, such as inner diameter, channel width, and combustor chamber length, could be determined by the propellant injection height to sustain rotating detonation. George et al. [10] examined the effect of detonation cell size and channel width on the propagation state of waves, using an $\mathrm{H}_{2}-\mathrm{O}_{2}-\mathrm{N}_{2}$ mixture, and revealed the relationship between number of waves and detonation perimeter. Nakayama et al. experimentally investigated the effect of the inner radius of curvature of the curved channel on the stability of detonation wave propagation [11].

The propulsive performance of RDE and PDE have been widely investigated by many institutions $[6,7,9,12-23,29,30]$. Kindracki et al. [12] measured the thrust and specific impulse of RDE under 0.5 bar. Yi et al. [13] demonstrated numerically that the specific impulse of RDE was unaffected by the number of detonation waves. Another numerical simulation study by $\mathrm{Wu}$ et al. [14] investigated the effect of total pressure on the specific impulse of RDE. The effects of RDE inner-wall radius were investigated numerically and experientially. A numerical simulation by Yao et al. [15] showed the flow structure of a hollow RDE without an inner-wall cylinder. Kawasaki et al. [16] investigated the effect of RDE inner radius, including a hollow RDE, on propulsive performance and the propagation structure of the detonation wave and proposed the critical inner diameter for sustaining thrust performance. A low-order parametric analysis of RDE by Mizener and $\mathrm{Lu}$ [17] revealed the effect of design parameters on thrust performance. Using a twodimensional (2-D) simulation model, Schwer and Kailasanath [18] varied the pressure ratio of the stagnation and backpressure, between 2.5 and 20, and found that it could affect the specific impulse and detonation wave heights.

Thrust performance of an RDE with converging nozzle (i.e., geometric throat) has been also investigated [19-23]. Kasahara et al. [19] explored the performance gain of an RDE with a converging-diverging nozzle and achieved almost the same characteristic exhaust velocity as that of constant-pressure combustion rockets. Frolov et al. [20] conducted large-scale RDE thrust measurement and found that attaching a nozzle or reducing the air injection area could increase in the number of detonation waves and thrust. Performance measurement done by Rankin et al. [21] showed that changing RDE exit geometry from bluff body to an aerospike could improve the specific thrust, especially, the choked aerospike design indicated that there was additional performance to be realized with additional choking of the flow beyond the thermal choke in the detonation channel. Fotia et al. [22] experimentally found stagnation pressure increases of between 3 and $7 \%$ for RDE with a geometric converging section. Fotia et al. [23] also attempted the experimental scaling of thrust performance of $\overline{\mathrm{RDE}}$ with parameters like propellant mass flux, air injection area expansion ratio, and nozzle area ratio. At the same mass flux condition, they found a tradeoff space in which fuel efficiency and effective usage of feed stagnation pressure could be exchanged [23].

Considering the design of thrusters, the most important parameter should be specific impulse $I_{\mathrm{sp}}$, defined by

$$
I_{\mathrm{sp}}=\frac{F}{\dot{m} g}
$$

The specific impulse can be determined by the combination of propellants, state of combustion, and the pressure ratio between combustion chamber stagnation pressure and backpressure. Ideal specific impulse under proper expansion can be calculated as

$$
I_{\mathrm{sp}, \mathrm{opt}}=\frac{1}{g} \sqrt{\frac{2 \gamma \mathrm{RT}_{o, c}}{\gamma-1}\left\{1-\left(\frac{p_{b}}{p_{o, c}}\right)^{((\gamma-1) / \gamma)}\right\}}
$$

Considering the fundamental isentropic nozzle theory, combustion chamber stagnation pressure should be proportional to throat mass flux. However, for an RDE, with a complex and transient flowfield, what the relation between combustion chamber pressure and throat mass flux should be and how the specific impulse behaves with a change in the pressure ratio for the range have not yet been clarified. This means that design guidelines for the throat, mass flow rates, and operating backpressure of an RDE to achieve a target thrust have not yet been identified.

Even though an RDE could be operated without a throat, highheat-load problems were not inevitable. High-frequency analysis of heat flux [24] and steady-state analysis [25,26,28,29] of RDE have been conducted. Theuerkauf et al. [24] developed a high-frequency response heat-flux gauge and revealed periodic heat flux in RDE caused by the rotating detonation wave. Quasi-steady heat transfer measurements are also important to determine the materials and thickness of chamber walls as well as cooling methods. Bykovskii and Vedernikov [26] revealed that the location of maximum temperature corresponded to the height of detonation waves. Braun et al. [27] numerically quantified the convective heat flux in RDE using a reduced-order model and identified the highest time-averaged heat fluxes at the location of the triple point. Stevens et al. [28] conducted water-cooled RDE experiments and measured outer-wall 
bulk heat flux calorimetrically. They found that the heat flux and heat transfer coefficient increased as mass flux, specific heat addition, and detonation frequency increased [28].

Ishihara et al. [29] conducted RDE combustion tests without cooling for 6-10 s using heat-resistant material, a carbon-carbon composite $(\mathrm{C} / \mathrm{C})$. They measured heat flux and thrust simultaneously, but after the test, they observed $\mathrm{C} / \mathrm{C}$ damage caused by oxidization [29]. Using heat-resistant material is one possible solution for protecting the combustor wall, but the problem could hinder longer combustion and potentially reduce RDE performance due to the loss of oxidizer entering the combustor. However, few studies have considered the governing parameters of wall heat flux in different RDE geometries or effective ways to improve carbon wall compatibility with RDE.

In this study, we conducted thrust measurements of ethylene/ gas-oxygen RDE with three throat geometries, including a throatless RDE, inside a $30.1 \mathrm{~m}^{3}$ vacuum chamber to simulate various backpressures. The first major scope of this work is the relation between RDE chamber pressure and equivalent throat mass flux defined by the geometrically minimum flow area. The second major scope is the specific impulse of RDEs with different throat geometries for a wide range of back-pressure. Additionally, we report and summarize our heat flux measurements of combustion tests from several-second combustion to discuss the effect of RDE channel mass flux and $\mathrm{C} / \mathrm{C}$ wall compatibility with different injection schemes.

\section{Experimental Facility}

Figure 1 presents a schematic view (Fig. 1a) and photographs (Fig. 1b) of the thrust measurement stand in a vacuum chamber. In this study, we measured thrust, pressure, and wall temperature and recorded high-speed imaging of the detonation channel from the aft end of the RDE, using a high-speed camera (SA5, Photron). Thrust was measured with a load cell attached to the thrust stand inside the vacuum chamber. The $30.1 \mathrm{~m}^{3}$ volume vacuum chamber was connected to a vacuum pump and allowed simulation of initial backpressure conditions ranging from sea level to $0.6 \mathrm{kPa}$. The vacuum chamber pressure was monitored by a Pirani vacuum pressure gauge (ULVAC GP-1S) and a pressure transducer (KELLER Piezoresistive Pressure Transmitters Series 23) connected to the side wall of the chamber.

In this study, we used five different RDE geometries, including throat, injector, and combustor size. We defined the $z$ axis as the bottom of the combustor toward the downstream. We also defined the $r$ axis from the center of the RDE toward the radius. For throatless RDE, we defined equivalent throat area $A_{\text {th }}$ as the detonation channel area. When the RDE had a geometric throat, $A_{\text {th }}$ was equal to the geometric throat area. The contraction area ratio $\varepsilon_{c}$ was defined by the ratio of $A_{\mathrm{th}}$ and detonation channel area $A_{\mathrm{ch}}$ as

$$
\varepsilon_{c}=\frac{A_{\mathrm{ch}}}{A_{\mathrm{th}}}
$$

Table 1 summarizes five RDE geometries used in this study.

Thrust measurement of the RDE with $A_{\mathrm{ch}}=640.4 \mathrm{~mm}^{2}$, shown in Fig. 2, was conducted by Kasahara et al. [19]. This RDE was made of copper $(\mathrm{C} 1100)$ for thermal conduction purposes. The inner radius was $r_{i}=30.25 \mathrm{~mm}$, channel width was $\Delta=3.2 \mathrm{~mm}$, and combustion chamber length was $L_{c}=48 \mathrm{~mm}$. The RDE had a $30 \mathrm{deg}$ conical plug, 72 fuel-injection holes $0.5 \mathrm{~mm}$ in diameter, and a $0.3-\mathrm{mm}$-wide oxidizer injection slot. To measure a steady, timeaveraged detonation channel pressure, we used a capillary tube attenuated pressure (CTAP) arrangement with KELLER Piezoresistive Pressure Transmitters Series 23 in this study. This transmitter had a frequency response of $1 \mathrm{kHz}$. The pressure sensor tap was located at the bottom of the combustor $(0.5 \mathrm{~mm}$ diameter). The tap was connected to $80 \mathrm{~mm}$ long tube of $1 / 4$ in. outer diameter.

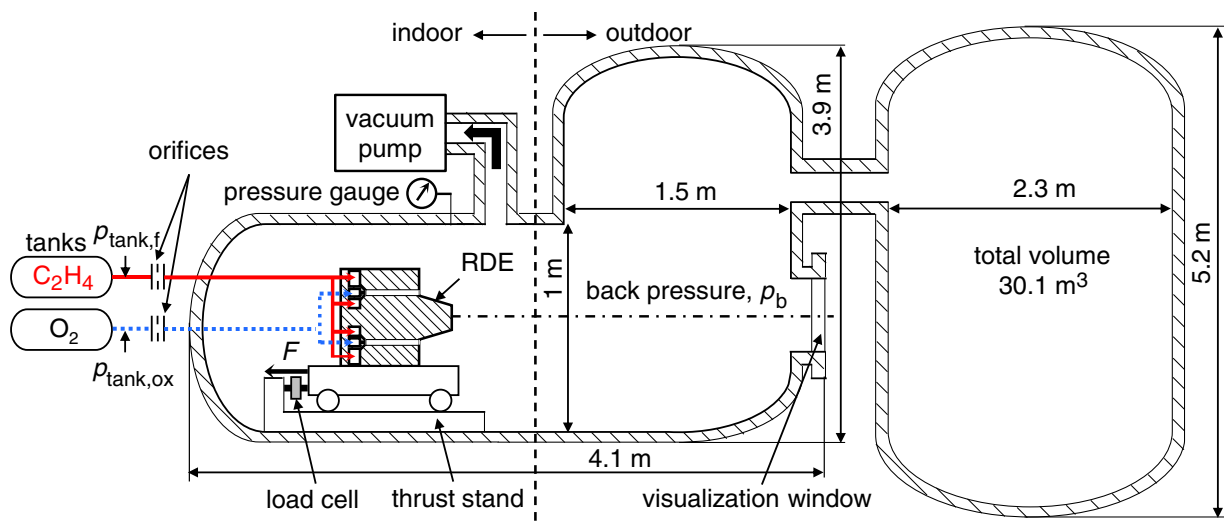

a) Schematic view of vacuum chamber experiments

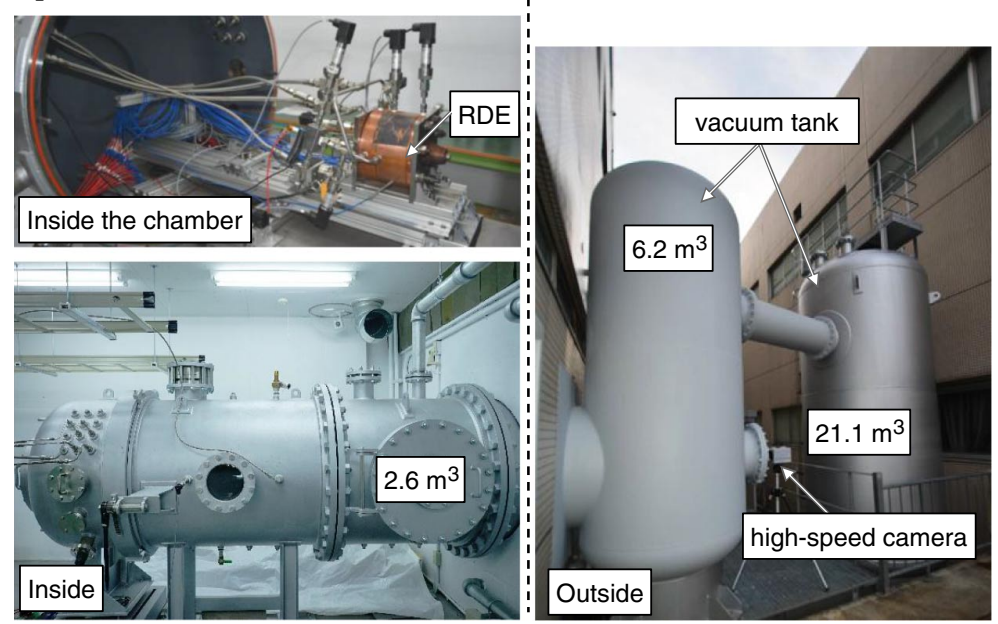

b) Photographs of vacuum chamber

Fig. 1 Schematic of experiment to measure RDE thrust. 
Table 1 Geometric parameters of RDEs for this study

\begin{tabular}{lcccccccc}
\hline \hline Geometry & $\varepsilon_{c}=A_{\mathrm{ch}} / A_{\mathrm{th}}$ & Injector & $\Delta, \mathrm{mm}$ & $A_{\mathrm{ch}}, \mathrm{mm}^{2}$ & $r_{i}, \mathrm{~mm}$ & $L_{c}, \mathrm{~mm}$ & $p_{c}$ position, $\mathrm{mm}$ & $T$ position, $\mathrm{mm}$ \\
\hline 1 & 1 & Slit & 3.2 & 640.4 & 30.25 & 48 & 0 & $8,24,40$ \\
2 & 1 & Triplet & 8 & 1759 & 31 & 75 & 5 & $10,30,50$ \\
3 & 2.5 & Doublet & 8 & 1759 & 31 & 70 & 0 & $2,9,18,35,65$ \\
4 & 8 & Doublet & 8 & 1759 & 31 & 70 & 0 & $2,9,18,35,65$ \\
5 & 8 & Triplet & 8 & 1759 & 31 & 75 & 5 & $10,30,50$ \\
\hline \hline
\end{tabular}

It should be noted that chamber pressure $p_{c}$, at $z=0$, could not reach an equilibrium state when the test duration was less than $1 \mathrm{~s}$ due to the small diameter of the pressure-sensing hole. Thermocouples were inserted at $z=8,24$, and $40 \mathrm{~mm}$. All thermocouples were attached to the wall $2 \mathrm{~mm}$ from the RDE outer combustor wall in this study.

The RDE with $A_{\mathrm{ch}}=1759 \mathrm{~mm}^{2}$ had an inner radius of $r_{i}=31 \mathrm{~mm}$ and a channel width of $\Delta=8 \mathrm{~mm}$, as shown in Fig. 3 . We tested three throat configurations of $\varepsilon_{c}=1,2.5$, and 8 for this study. For $\varepsilon_{c}=2.5$, the width of the symmetric throat was $3.2 \mathrm{~mm}$, and the

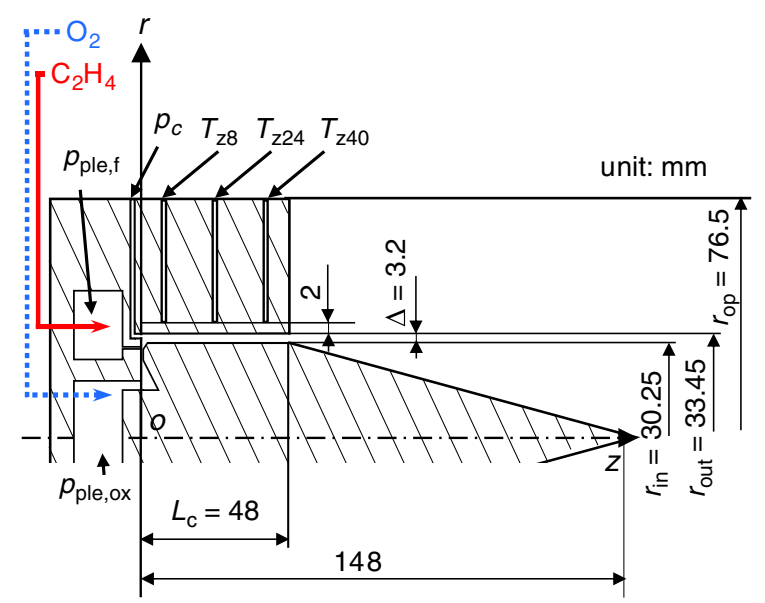

Fig. 2 Schematic of annular RDE; geometry $1, A_{\mathrm{ch}}=640.4 \mathrm{~mm}^{2}$. outer exit width was $8 \mathrm{~mm}$. The length from the entrance of convergent section to the throat and that from the throat to the outer nozzle exit were both $6 \mathrm{~mm}$. For $\varepsilon_{c}=8$, the width of the symmetric throat was $1 \mathrm{~mm}$, and the outer exit width was $16 \mathrm{~mm}$. The length from the entrance of convergent section to the throat and that from the throat to the outer nozzle exit were 10 and $16 \mathrm{~mm}$, respectively.

We used two types of injector geometries, doublet and triplet, for this study. The material of the outer wall used either copper or $\mathrm{C} / \mathrm{C}$ composite. To see the effect of injector shape on wall compatibility, two injectors were used. One injector scheme was doublet-impinging injection, which had 120 sets of 1-mm-diam fuel-injection holes and an oxidizer hole (1 $\mathrm{mm}$ diameter). The combustion chamber length $L_{c}$ was $70 \mathrm{~mm}$, and the C/C composite wall section was $L_{c c}=70 \mathrm{~mm}$ and had a truncated conical plug nozzle. Measuring chamber pressure $p_{c}$ was taken through the hole $(2 \mathrm{~mm})$ located at the bottom of combustor, $z=0$. Thermocouples were inserted at $z=2,9,18,35$, and $65 \mathrm{~mm}$.

The other injector scheme was triplet; it had 72 sets of two fuel injection holes (1 mm diameter) and an oxidizer hole $(1.4 \mathrm{~mm}$ diameter) between fuel holes. It had a combustion chamber length of $L_{c}=75 \mathrm{~mm}$ and a truncated conical plug nozzle. The length of the $\mathrm{C} / \mathrm{C}$ composite wall section $L_{c c}$ was $60 \mathrm{~mm}$. This was different from the doublet case, but because oxidization happened only in the vicinity of the injector surface, this difference was not important to a comparison of wall compatibility with injector shape. Measurements of chamber pressure $p_{c}$ were taken by the same CTAP technique mentioned previously, through the hole $(2 \mathrm{~mm})$ located at $\mathrm{z}=5 \mathrm{~mm}$, which was as close to the bottom of combustor as possible because the entire bottom surface of the triplet injector had injection holes.

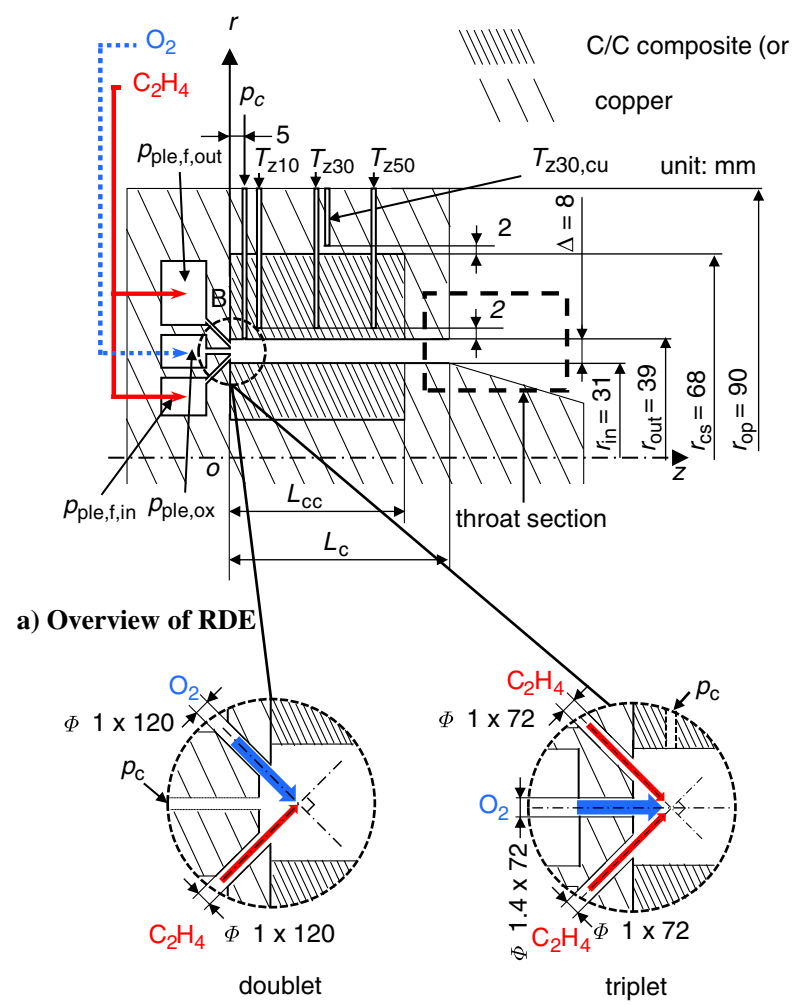

c) Injector geometry

triplet

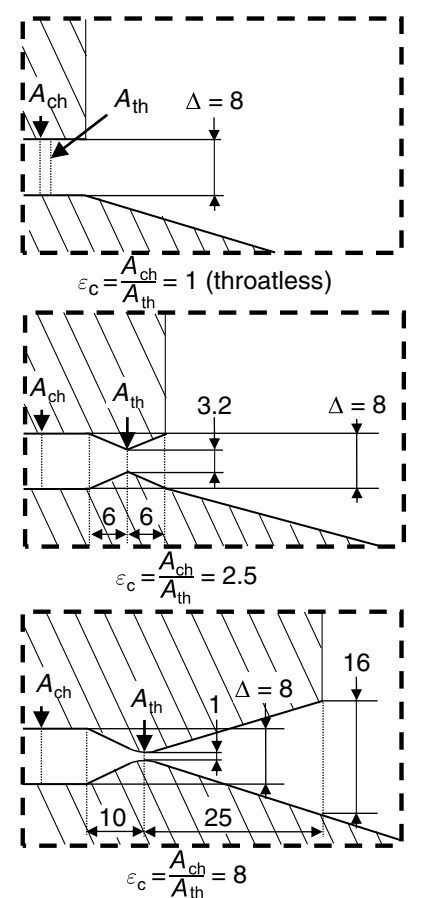

b) Throat geometry

Fig. 3 Schematic of annular RDE; geometries 2-5, $A_{\mathrm{ch}}=1759 \mathrm{~mm}^{2}$ : a) overview of RDE, b) throat geometry, and c) injector shape. 
Thermocouples were inserted at $z=10,30$, and $50 \mathrm{~mm}$. The other thermocouple $T_{z 30 \text {,cu }}$ was inserted near the radial position of the contact surface between the perimeter copper and $\mathrm{C} / \mathrm{C}$ composite, $r_{c}=86 \mathrm{~mm}$, to define the timing of the thermal equilibrium after the combustion test.

We used gaseous ethylene and gaseous oxygen as the propellants. Each mass flow rate was controlled and determined by choking orifices upstream of the RDE feeding line. The following choking equation was used to determine ideal mass flow rate $\dot{m}_{i}$ :

$$
\dot{m}_{i}=\frac{\bar{p}_{\text {tank }}\left(\pi d_{\text {ori }}^{2} / 4\right)}{\sqrt{\mathrm{RT}_{\tan k}}} \sqrt{\gamma\left(\frac{2}{\gamma+1}\right)^{((\gamma+1) /(\gamma-1))}}
$$

Each feeding tank volume ( $48 \pm 1$ liters) is large enough to assume that mass flow rates were constant in range of measurement error during typical operation (less than $1 \mathrm{~s}$ ). Mass flow rate calibration was done separately before combustion experiments to determine the mass flow coefficient $C_{d}$ from operational duration $t_{\text {ope }}$ and tank mass decrease $\Delta m$ as follows:

$$
C_{d}=\frac{\Delta m}{t_{\text {ope }}} \frac{1}{\dot{m}_{i}}
$$

Mass decrease was determined by electric balance or the decrease in internal tank pressure. For some longer-duration tests, mass flow rate calibration was done $[19,29,30]$. Actual mass flow rate $\dot{m}$ could be calculated by

$$
\dot{m}=C_{d} \dot{m}_{i}
$$

For a throatless RDE, plenum pressure was sufficiently higher than combustor pressure before ignition. Ideal mass flow rate could also be calculated using time-averaged plenum pressure before ignition:
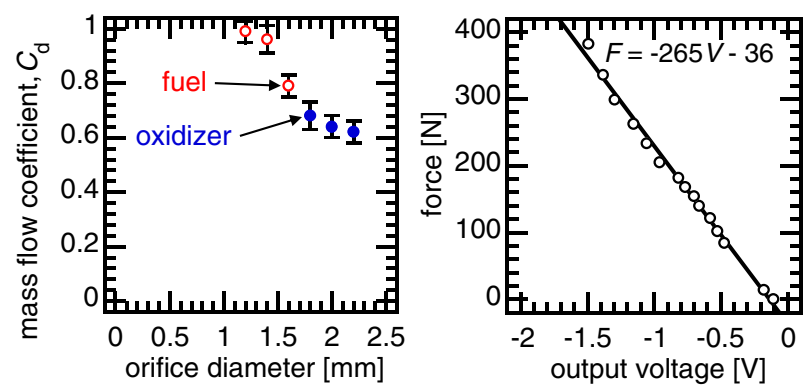

a) Orifice coefficient

b) Load cell output

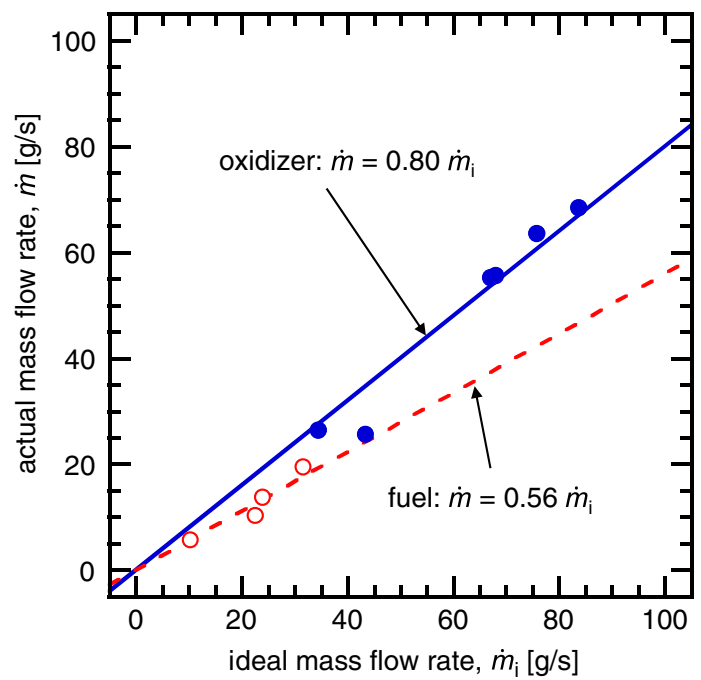

c) Mass flow rate calibration of injector

Fig. 4 Calibration results for a) flow coefficient of orifice, b) load cell output, and c) flow coefficient of triplet injector.

$$
\dot{m}_{i}=\frac{\bar{p}_{\mathrm{ple}} A_{\mathrm{inj}}}{\sqrt{\mathrm{RT}_{\tan k}}} \sqrt{\gamma\left(\frac{2}{\gamma+1}\right)^{((\gamma+1) /(\gamma-1))}}
$$

Here, $A_{\text {inj }}$ was the total injector area. Representative calibration results are shown in Fig. 4. For simplicity, we only show the mass flow rate calibration results of an RDE orifice in the doublet injector with $\varepsilon_{c}=8$ (Fig. 4a) and triplet injector with $\varepsilon_{c}=1$ (Fig. 4c). We estimated the uncertainty of the mass flow rate test, considering propagation of errors of each sensor and the standard deviation. Figure $4 \mathrm{c}$ shows only the inner fuel injector calibration result for simplicity because we obtained the same mass flow coefficient value (i.e., the slope of the calibration result) for the outer injector. The load cell was calibrated with known weights for four times and got slope with the average value of them for triplet, $\varepsilon_{c}=1$ case (Fig. $4 \mathrm{~b}$ ). We determined the uncertainty of the slope of load cell calibration result by the standard deviation of output voltage. Other mass flow rates and load cell calibration results are available in our other papers $[19,29,30]$.

\section{Experimental Results and Discussion}

A. Pressure in Combustor and Thrust Performance with Throat Mass Flux

Figure 5 shows a representative time history of a combustion experiment with a throatless RDE. From the visualization images, average detonation wave speed could be calculated as $2273 \mathrm{~m} / \mathrm{s}$ for this condition, as plotted in Fig. 5. The backpressure increased slightly from the initial backpressure $\bar{p}_{b, 1}$ to final backpressure $p_{b, 2}$ due to exhaust combustion gases filling the vacuum chamber. Therefore, average backpressure $p_{b}$ was determined by the following equation to evaluate propulsive performance. The uncertainty of $p_{b}$ was determined by the difference between $p_{b}$ and $p_{b, 1}$ (or $p_{b, 2}$ ):

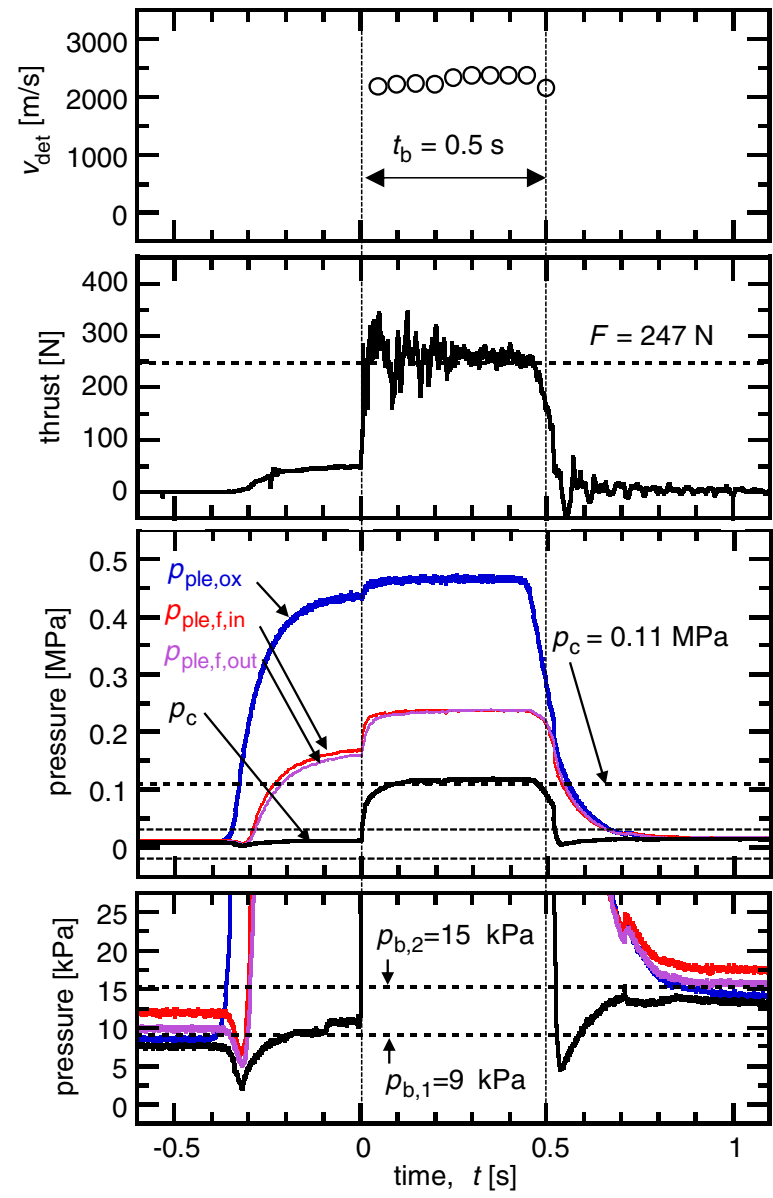

Fig. 5 The history of detonation wave speed, thrust, pressure, and close-up of pressure from $\mathrm{Sh} \# 8,\left(p_{b}=12 \pm 6 \mathrm{kPa}\right)$. 
Table 2 Experimental conditions and results, including sh\#1, 2, and 3 from Kasahara et al. [19] and sh\#9 and 10 from Ishihara et al. [29]

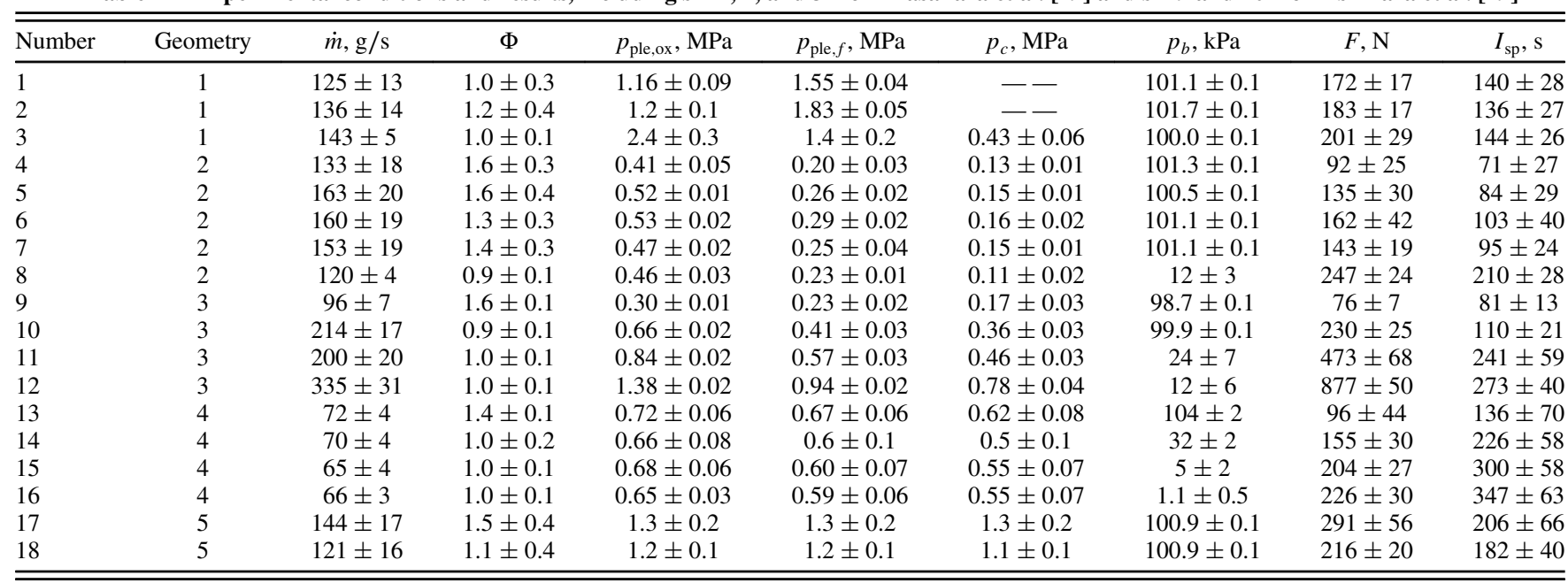

$$
p_{b}=\frac{p_{b, 1}+p_{b, 2}}{2}
$$

The testing conditions and the results in this study are summarized in Table 2. The uncertainty of mass flow rate, mass flux, and equivalence ratio was determined by the error of mass flow coefficient of orifice or mass flow coefficient of injector described previously. Thrust was time averaged during burn time. The value of thrust oscillated due to the mechanical vibration of thrust stand caused by the RDE ignition. We considered the uncertainty of thrust as the error of load-cell calibration and the standard deviation of thrust during operation. The uncertainty of pressure was also determined by the standard deviation of each value during the operation. The error of specific impulse was estimated by propagation of uncertainty of mass flow rate and thrust.

When considered in fundamental isentropic flow theory, the stagnation pressure in the combustor $\left(p_{o, c}\right)$ at the choked condition can be expressed using the throat mass flux as

$$
p_{o, c}=\frac{\sqrt{\mathrm{RT}_{o, c}}}{\sqrt{\gamma(2 /(\gamma+1))^{((\gamma+1) /(\gamma-1))}}} \frac{\dot{m}}{A_{\mathrm{th}}}
$$

Assuming that differences in the ratio of specific heat, gas constant, and stagnation temperature were small, it would be expected that chamber pressure $p_{c}$ should be in proportion to throat mass flux. The trend of chamber pressure obtained through increasing the throat mass flux is shown in Fig. $\underline{6}$. We computed $\gamma, R$ (i.e., the molecular weight of products), and $T_{o, c}$ from NASA-CEA [31] as a constant-pressure combustion for all testing conditions in Table 2. We then calculated the coefficient of the throat mass flux using Eq. (9) for each experimental condition to show the uncertainty of the coefficients, determined by the maximum and minimum value of them. The solid line is a regression line generated by our measured experimental data plots. As expected, chamber pressure was approximately proportional to throat mass flux, even though chamber geometries and injector schemes were different. This trend may be interpreted as characteristic exhaust velocity $c^{*}$, defined in Eq. (10), held constant at $1.8 \times 10^{3} \mathrm{~m} / \mathrm{s}$ regardless of throat and injector geometries:

$$
c^{*}=\frac{p_{o, c} A_{t}}{\dot{m}}
$$

We nondimensionalized chamber pressures by the ideal $p_{o, c, i}$ from NASA-CEA [31] using the same mass flow rate and throat area for each condition assuming choking condition at equivalent throat area for each case as shown in Fig. 7. Nondimensionalized combustor pressures are the same as $c^{*}$ efficiency. For most test cases in this study, $c^{*}$ efficiency was almost close to 1 , regardless of injector and throat geometries.
In Fig. 6, it should also be noted that, in addition to converging nozzle conditions, throatless conditions were on the slope regardless of the backpressure conditions. This implies that a minimum crosssectional area (i.e., the geometric throat in combustors with a throat) can determine the chamber pressure, and RDE operation could achieve almost perfect combustion. This suggestion seems oversimplified because the pressure reading in one case might be closer to the stagnation value, whereas it might not be in another due to different chamber configurations. However, the overall trend is applicable for a rough prediction to determine a chamber pressure and the operating conditions of mass flow rates, and it showed that RDE could achieve ideal $c^{*}$ against constant-pressure combustors under the same operating conditions.

From a qualitative perspective, an increase in the ratio between combustion chamber pressure and backpressure should give a higher specific impulse. Figure $\underline{8}$ shows the relation between specific impulse and pressure ratio, defined as $p_{c} / p_{b}$. The solid slope represents the ideal specific impulse curve under correct expansion calculated by NASA-CEA [31] as a reference (calculated initial condition was determined by the average value of all experimental conditions). At $p_{c} / p_{b}$ of $1.28-515$, RDE could achieve almost the same level, at least at approximately $80 \%$, of specific impulse of the constant-pressure combustion rockets, regardless of whether or not RDE had a geometric throat. However, the calculation

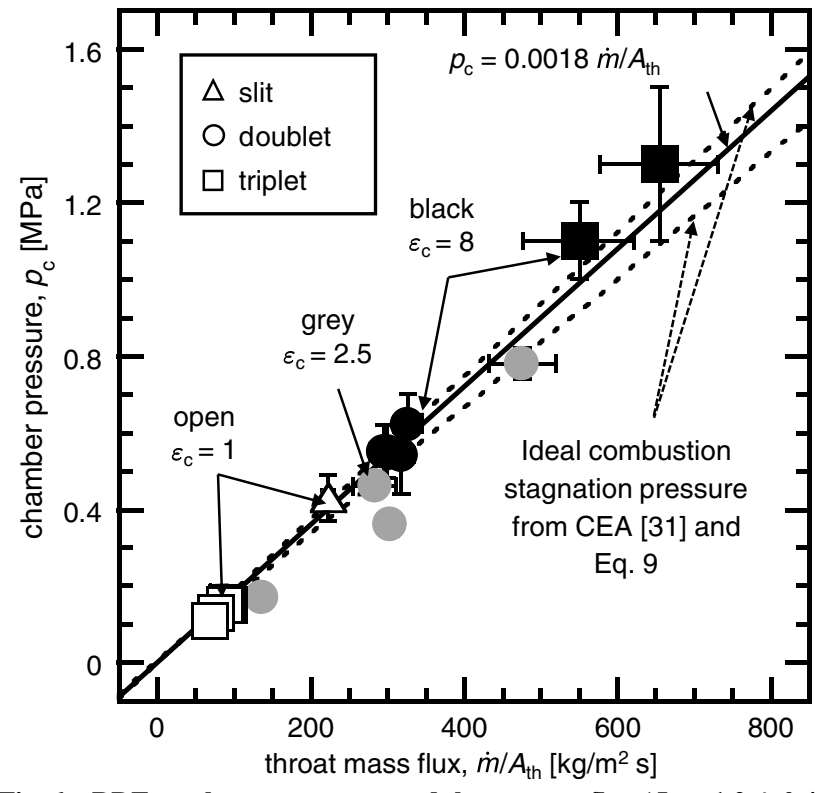

Fig. 6 RDE combustor pressure and throat mass flux $(\Phi=1.2 \pm 0.4)$. 


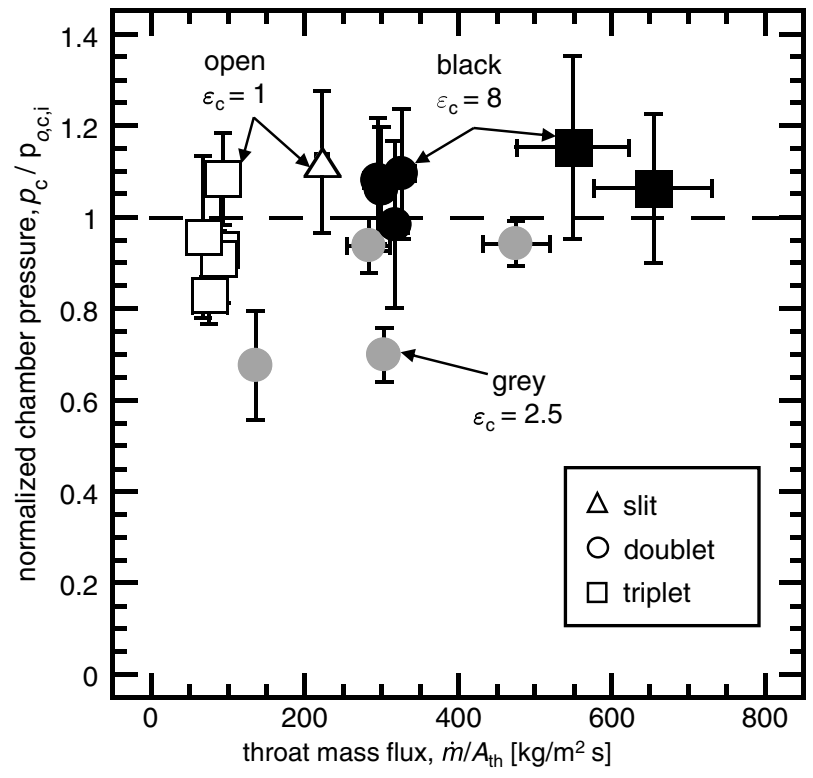

Fig. 7 Normalized RDE combustor pressure and throat mass flux $(\Phi=1.2 \pm 0.4)$.

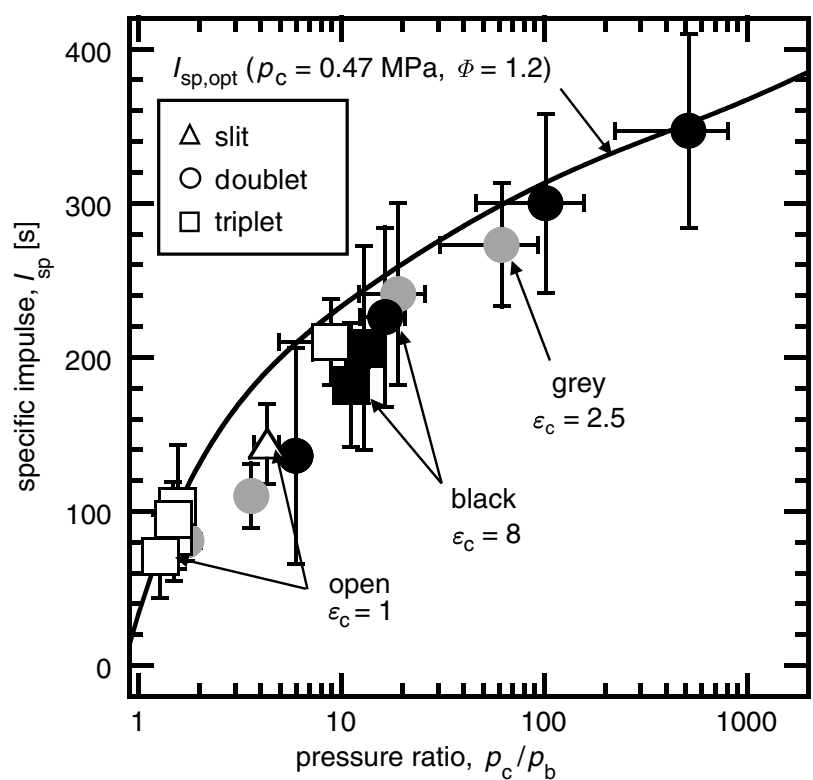

Fig. 8 Specific impulse and RDE combustor pressure ratio $\left(\Phi=1.2 \pm 0.4, p_{b}=1.1-104 \mathrm{kPa}\right)$.

result given by NASA-CEA [31] assumed that flow was always choked at a throat, and so it is important to discuss the region where $p_{c} / p_{b}$ was above 2 . To assess the true performance of RDEs, we nondimensionalized $I_{\mathrm{sp}}$ by the ideal specific impulse $I_{\mathrm{sp}, \text { opt }}$ of a constant-pressure engine operating with the measured mass flow and backpressure conditions as shown in Fig. 9. In Fig. 9, normalized specific impulse gradually reached unity as $p_{c} / \bar{p}_{b}$ increased. Because Fig. 7 indicated that $c^{*}$ was held approximately constant in this study, the performance loss from the ideal specific impulse should be mainly due to the nozzle effect. The optimum area ratio of the exit area $A_{e}$ to the throat area for a given pressure ratio was

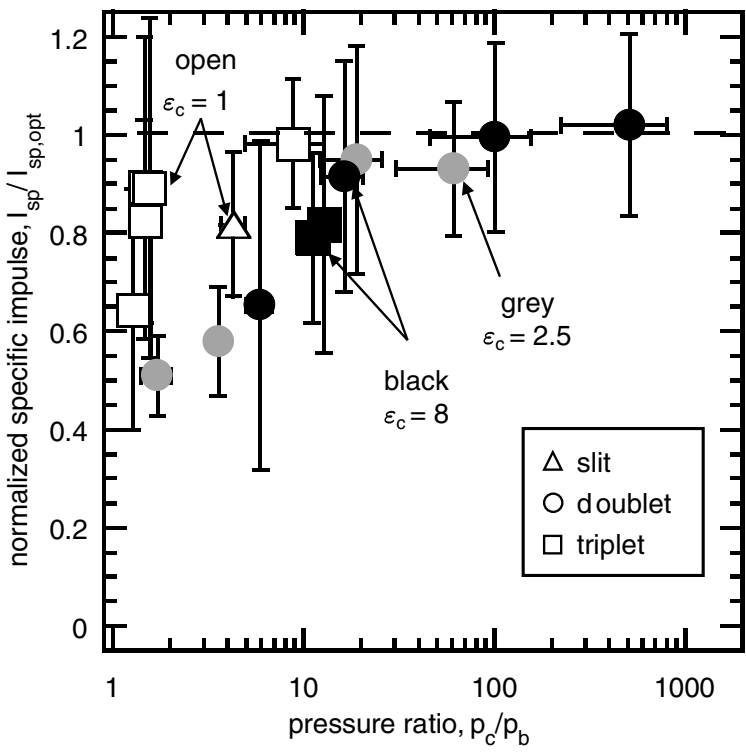

Fig. 9 Normalized specific impulse and RDE combustor pressure ratio $\left(\Phi=1.2 \pm 0.4, p_{b}=1.1-104 \mathrm{kPa}\right)$.

RDEs with a throat in this study had outer diverging nozzles. If we consider the exit area for RDE with a throat in this study as the annular exit area at the end of the diverging section, $A_{e} / A_{\mathrm{th}}$ for geometry 3 $\left(\varepsilon_{c}=2.5\right)$, and geometries 4 and $5\left(\varepsilon_{c}=8\right)$ were 2.5 and 16 , respectively. For $\gamma=1.1$ (output from NASA-CEA [31] at the reference condition), correct expansion occurs around $p_{c} / p_{b}$ as 10 and 100 for $\varepsilon_{c}=2.5$ and $\varepsilon_{c}=8$, respectively. In fact, the nondimensionalized specific impulse of $\varepsilon_{c}=2.5$ approached the ideal value above $p_{c} / p_{b}=10$. The same trend appeared for $\varepsilon_{c}=8$ as experimental results approached unity above $p_{c} / p_{b}=100$.

Above those optimum $p_{c} / p_{b}$, specific impulses were in relative agreement with the ideal curve. Because they also had an inner aerospike plug nozzle, it might have worked to further expand the flow. Above $p_{c} / p_{b}=2$, throatless RDE could achieve $82 \pm 15 \%$ of $I_{\text {sp,opt }}$ with a slit injector and $98 \pm 13 \%$ of $I_{\text {sp }, \text { opt }}$ with a triplet injector. It is difficult to determine where $A_{e}$ is for the throatless RDE. However, because the throatless RDE in this study did not have outer diverging nozzles, but an inner aerospike nozzle, considering the exit area as the outer combustor area $\pi r_{\text {out }}^{2}$ was thought reasonable. In this assumption, $A_{e} / A_{\text {th }}$ for geometries 1 and 2 were 5.5 (optimum $p_{c} / p_{b} \approx 10$ ) and 2.7 (optimum $p_{c} / p_{b} \approx 30$ ), respectively. The specific impulse at $p_{c} / p_{b}=9$ for geometry 2 was close to the ideal value and seemed to correspond to the correct expansion condition given by the defined $A_{e} / A_{\mathrm{th}}$. At $p_{c} / p_{b}=4$ for geometry 1 , the specific impulse was relatively lower. Based on the assumption of $A_{e} / A_{\text {th }}$ for the throatless RDE, correct expansions occurred around $p_{c} / p_{b} \approx 30$ for geometry 1 , which was far from the experimental condition $p_{c} / p_{b}=4$. This low-pressure ratio might cause overexpansion and performance loss. However, when we determined chamber pressure (i.e., throat mass flux as shown in Fig. 6) and backpressure, RDEs in this study could achieve almost the same level of ideal specific impulse as constant-pressure combustion rockets.

\section{B. Heat Flux and Channel Mass Flux}

Because we discussed the effect of throat mass flux and $p_{c} / p_{b}$ on propulsive performance in the previous section, we now extend this framework to heat load. From the temperature history obtained from thermocouples, we calculated wall heat flux in the RDE combustor outer wall based on a textbook analysis of one-dimensional (1-D) axisymmetric heat conduction using the difference method as

$$
\left(\frac{A_{e}}{A_{\mathrm{th}}}\right)_{\mathrm{opt}}=\sqrt{\left(\frac{\gamma-1}{2}\right)\left(\frac{2}{\gamma+1}\right)^{((\gamma+1) /(\gamma-1))} /\left\{\left(\frac{p_{b}}{p_{o, c}}\right)^{2 / \gamma}-\left(\frac{p_{b}}{p_{o, c}}\right)^{((\gamma+1) / \gamma)}\right\}}
$$


Table 3 Thermal properties of material for this study

\begin{tabular}{lcccc}
\hline \hline & $\begin{array}{c}\text { Thermal } \\
\text { conductivity, } \\
\mathrm{W} / \mathrm{m} \cdot \mathrm{K}\end{array}$ & $\begin{array}{c}\text { Density, } \\
\mathrm{kg} / \mathrm{m}^{3}\end{array}$ & $\begin{array}{c}\text { Specific heat, } \\
\mathrm{J} / \mathrm{kg} \cdot \mathrm{K}\end{array}$ & $\begin{array}{c}\text { Thermal } \\
\text { diffusivity, } / \mathrm{s}^{2}\end{array}$ \\
Material & 403 & 8930 & 385 & $1.17 \times 10^{-4}$ \\
Copper & 35 & 1650 & 720 & $2.95 \times 10^{-4}$ \\
C/C & & & & \\
composites & & &
\end{tabular}

$$
T_{j}^{t+1}=T_{j}^{t}+\frac{a \Delta t}{\Delta r^{2}}\left\{\left(1+\frac{\Delta r}{2 r_{j}}\right) T_{j+1}^{t}-2 T_{j}+\left(1-\frac{\Delta r}{2 r_{j}}\right) T_{j-1}^{t}\right\}
$$

where $a$ is a thermal diffusivity, the time step $\Delta t=1 \mathrm{~ms}$, and the special step $\Delta r=1 \mathrm{~mm}$. Although 1-D might be an overly simplified model, it can give a sense of the heat-flux trend. Here, we only considered test cases using the $\mathrm{C} / \mathrm{C}$ composite for $\mathrm{RDE}$ combustor walls and conducted combustion tests for several seconds to get a steady value of heat flux for 1-D analysis. The initial condition was given by atmospheric temperature for each condition. Three boundary conditions were introduced.

1) At the outer-wall surface, wall heat flux $\dot{q}_{l}$ was a fitting parameter to determine the temperature in the combustor of this model using the least-squares method (time step of $\dot{q}_{l}$ was $200 \mathrm{~ms}$ ).

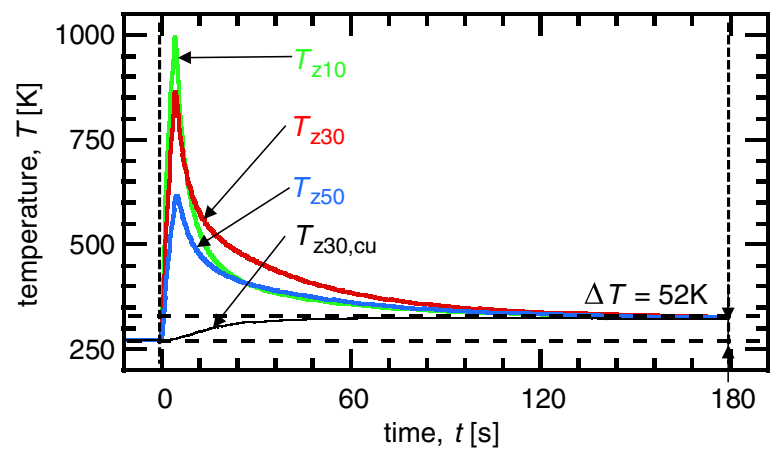

a) Temperature history for $180 \mathrm{~s}$

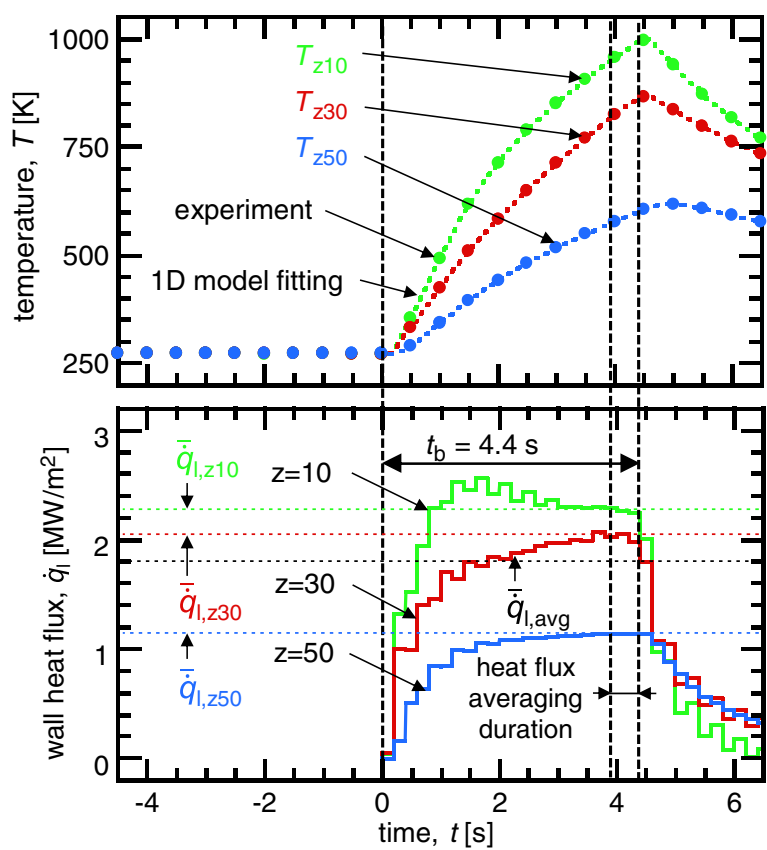

b) Temperature history for $6 \mathrm{~s}$ (detailed view)

Fig. 10 Temperature history and local heat flux from Sh\#4: a) temperature history for $180 \mathrm{~s}$, and b) temperature and heat-flux history for $6 \mathrm{~s}$.
2) At the contact surface $\left(r=r_{\mathrm{cs}}\right)$ of the $\mathrm{C} / \mathrm{C}$ composite and copper, contact was assumed to be perfect.

3) The outer peripheral element $\left(r=r_{\text {op }}\right)$ was adiabatic.

In addition, we also calculated average wall heat flux from the total temperature increase in the RDE combustor to compensate for measurement error of the temporal thermocouple response, using an adiabatic calorimetric method. The bulk wall heat flux into RDE combustor was calculated using the following equation:

$$
\overline{\dot{q}}_{c}=\frac{C \Delta T}{A_{s} t_{b}}
$$

where $C$ is the total heat capacity of the RDE, $\Delta T$ is the temperature rise of the entire RDE, $t_{b}$ is the burn time, and $A_{s}$ is the total axial surface area of the combustion chamber from the bottom to the nozzle tip. When we used all copper RDE, this analysis was also applied. The thermal properties given by the manufacturers for this study are summarized in Table 3 .

Figure 8 shows a representative result of temperature history and calculated wall heat flux. Figure $\underline{8 a}$ presents a long temperature
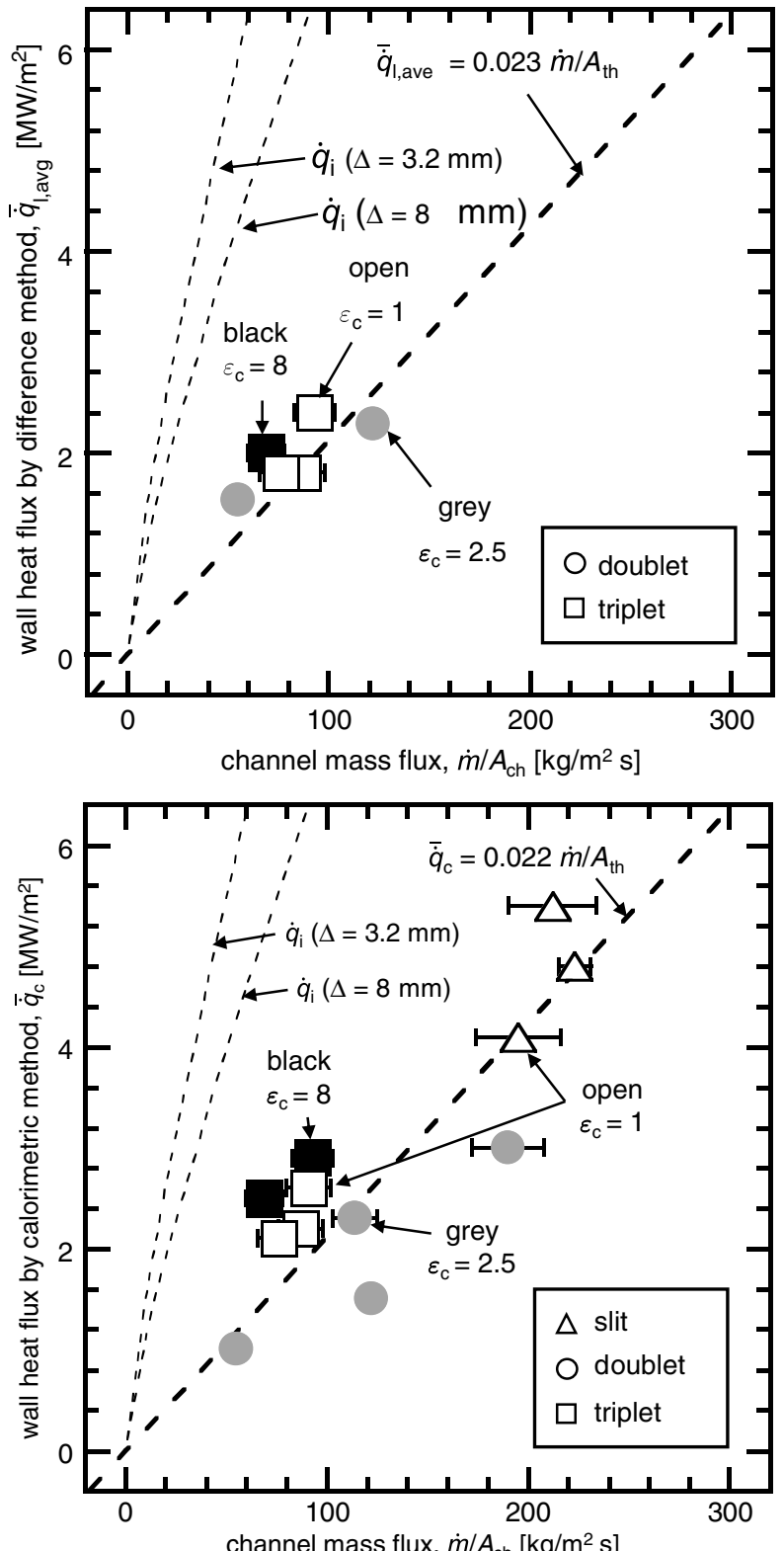

Fig. 11 Detonation channel mass flux and wall heat-flux distribution from the difference method (top) and calorimetric method (bottom) $(\Phi=1.2 \pm 0.4)$. 
Table 4 Experimental conditions for wall compatibility study (sh\#9 and 10 were measured by Ishihara et al. [29])

\begin{tabular}{lccccc}
\hline \hline Sh\# & Injector & $\dot{m}, \mathrm{~g} / \mathrm{s}$ & $\Phi$ & $\dot{m}_{\text {ox }}, \mathrm{g} / \mathrm{s}$ & $t_{\text {ope }}, \mathrm{s}$ \\
\hline 4 & Triplet & $133 \pm 18$ & $1.6 \pm 0.3$ & $91 \pm 13$ & $4.4 \pm 0.1$ \\
5 & Triplet & $163 \pm 20$ & $1.6 \pm 0.4$ & $112 \pm 17$ & $3.0 \pm 0.1$ \\
9 & Doublet & $96 \pm 7$ & $1.6 \pm 0.2$ & $65 \pm 6$ & $10.2 \pm 0.1$ \\
10 & Doublet & $214 \pm 17$ & $0.9 \pm 0.1$ & $169 \pm 17$ & $6.3 \pm 0.1$ \\
\hline \hline
\end{tabular}

history from ignition to $180 \mathrm{~s}$. The temperature of the outer copper casing $T_{z 30 \text {,cu }}$ and other temperature responses reached equilibrium at $180 \mathrm{~s}$. We then defined the whole temperature rise $\Delta T$ as that at $180 \mathrm{~s}$ from the beginning of combustion for all experimental cases. The top graph in Fig. 10b shows a short temperature history of $6 \mathrm{~s}$; the markers represent the temperature measured at each $0.5 \mathrm{~s}$, and the dotted line indicates the calculated temperature to fit the experimental value. The heat-flux distribution showed a decreasing trend as flow went through the exit. We defined the temporally averaged heat flux for each location as the averaged value during the final $0.5 \mathrm{~s}$ before the end of combustion because calculated heat flux needed time to reach a steady state. Then, we spatially averaged those three temporally averaged wall heat fluxes to obtain the average wall heat flux $\dot{q}_{l, \text { avg }}$.

The flowfield of RDE was high-frequency periodic, and the system considered a heat source term. However, if we consider the spatial and temporal average (i.e., homogeneous) temperature field throughout the combustor with a short heat-release zone compared to the entire combustor length, we should be able to treat the steady, turbulent heat transfer. In this case, correlations are generally expressed in terms of dimensionless variable groups such as Nusselt number $\mathrm{Nu}$, Prandtl number $\mathrm{Pr}$, and Reynolds number $R e$ :

$$
N u=c \operatorname{Re}^{m} \operatorname{Pr}^{n}
$$

The heat transfer coefficient is defined by

$$
h=\frac{\dot{q}_{w}}{T_{o, c}-T_{w}}
$$

Using the definitions for Nusselt number and Reynolds number, the equation can be expressed as

$$
\dot{q}_{w}=\frac{c_{1} k_{o, c} P r^{n}}{\mu^{m}} L^{m-1}\left(\frac{\dot{m}}{A}\right)^{m}\left(T_{o, c}-T_{w}\right)
$$

In this study, the variance of length scale $L$, which was the hydraulic diameter of the detonation channel, was only $4 \%$ for all
RDE configurations, and so it can be regarded as constant. Assuming that differences of other parameters, such as specific heat, viscosity, fluid thermal conductivity, and combustion gas temperature are small, we obtain

$$
\dot{q}_{w} \approx c_{1}\left(\frac{\dot{m}}{A}\right)^{m}\left(T_{o, c}-T_{w}\right)
$$

If $m$ is close to 1 , the wall heat flux should be almost proportional to mass flux. As we did for combustor pressures and specific impulses, we compared these measured mass fluxes with that of the steady constant combustion device. Because we considered the spatial and temporal average heat flux here, it should be reasonable to refer to the typical heat transfer problem of internal flow, such as the Dittus and Boelter equation [32] as

$$
N u=0.023 \operatorname{Re}^{0.8} \operatorname{Pr}^{0.4}
$$

We calculated viscosity by a textbook analysis [33] as

$$
\mu=\left(46.6 \times 10^{-10}\right) M^{0.5} T_{c}^{0.6}
$$

Here, $M$ is the molecular weight. Integrating Eqs. (14) and (16), we could compute the ideal wall heat flux of constant-pressure combustion $\dot{q}_{i}$. Figure 11 represents the wall heat flux obtained from the difference method based on 1-D heat transfer analysis (Fig. 11, top) and calorimetric method (Fig. 11, bottom) with the increase in channel mass flux. We also computed ideal wall heat flux $\dot{q}_{i}$ for geometry $1(\Delta=3.2 \mathrm{~mm})$ and geometries 2 to $5(\Delta=8 \mathrm{~mm})$ as a reference $\left(P r=0.8, T_{w}=300 \mathrm{~K}\right.$, and other calculated conditions were determined by NASA-CEA [31]; input parameters were $p_{c}=0.4 \mathrm{MPa}, \Phi=1.2$ ). As expected, average wall heat flux through the RDE channel was approximately proportional to the RDE channel mass flux, regardless of throat geometry. Average wall heat flux calculated by the calorimetric method $\overline{\dot{q}}_{c}$ was $16-23 \%$ higher than $\overline{\dot{q}}_{l \text {,ave }}$ for the same experimental conditions. This may have been due to the 2-D thermal diffusion formed at the throat. When combustors have a throat, the heat flux at the throat is expected to be higher than at other areas. Therefore, diffused heat from the throat section could slightly increase the average temperature compared to the 1-D heat transfer model. From the comparison of experimental heat flux with the ideal value, these orders seemed to be the same, but there was a discrepancy between the experimental value and ideal one. According to Fig. 7, $c^{*}$ efficiency was almost unity, and so the combustion temperature was unlikely to be quite lower than that of constant combustion. Therefore, constant and exponent of Eq. (16) might not be applicable to RDE even if we treated the RDE's temperature field as homogeneous. More precise measurements will
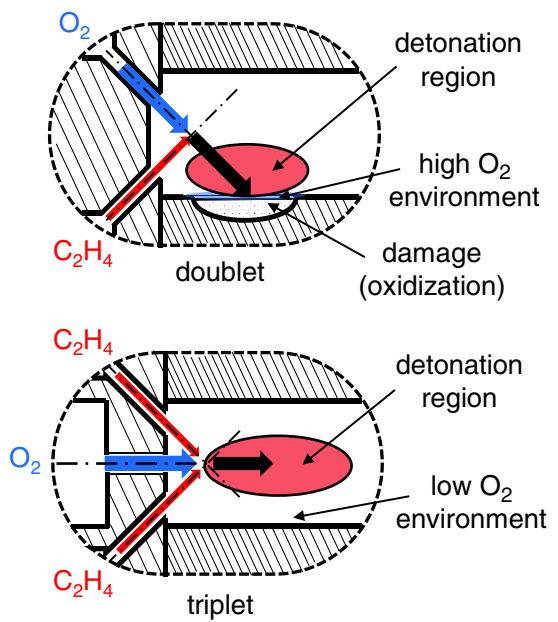

a) Schematic of $\mathrm{C} / \mathrm{C}$ damage of inner wall with doublet / triplet injector

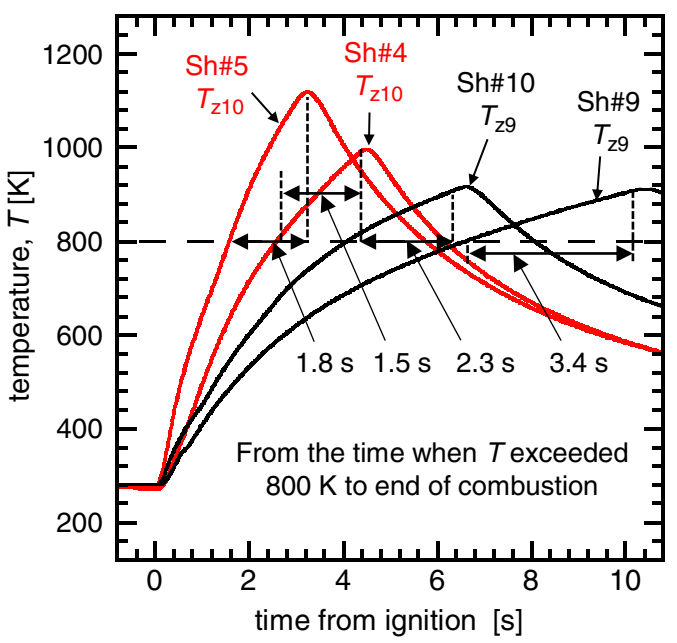

b) $\mathrm{C} / \mathrm{C}$ damage vs oxidizer mass

Fig. 12 Representations of a) schematic for comparison of $\mathrm{C} / \mathrm{C}$ wall damage, and b) temperature history and consumption time of oxidizer. 


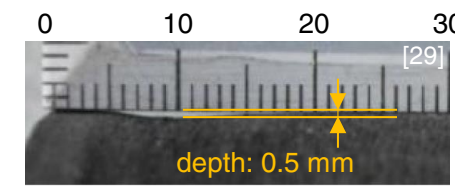

Sh\#9, $\dot{m}_{\mathrm{ox}}=65 \mathrm{~g} / \mathrm{s}, t_{\mathrm{b}}=10.2 \mathrm{~s}$, doublet

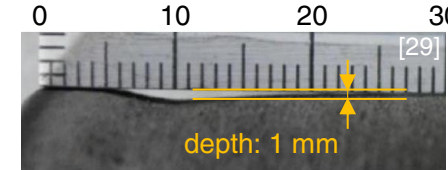

Sh\#10, $\dot{m}_{\mathrm{ox}}=169 \mathrm{~g} / \mathrm{s}, t_{\mathrm{b}}=6.3 \mathrm{~s}$, doublet

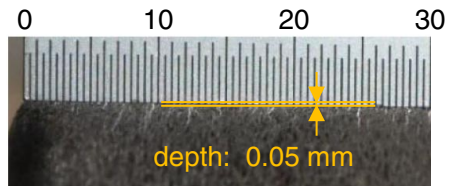

Sh\#4, $\dot{m}_{\mathrm{ox}}=91 \mathrm{~g} / \mathrm{s}, t_{\mathrm{b}}=4.4 \mathrm{~s}$, triplet

Sh\#5, $\dot{m}_{\text {ox }}=112 \mathrm{~g} / \mathrm{s}, t_{\mathrm{b}}=3.0 \mathrm{~s}$, triplet

a) Photographs of $\mathrm{C} / \mathrm{C}$ damage

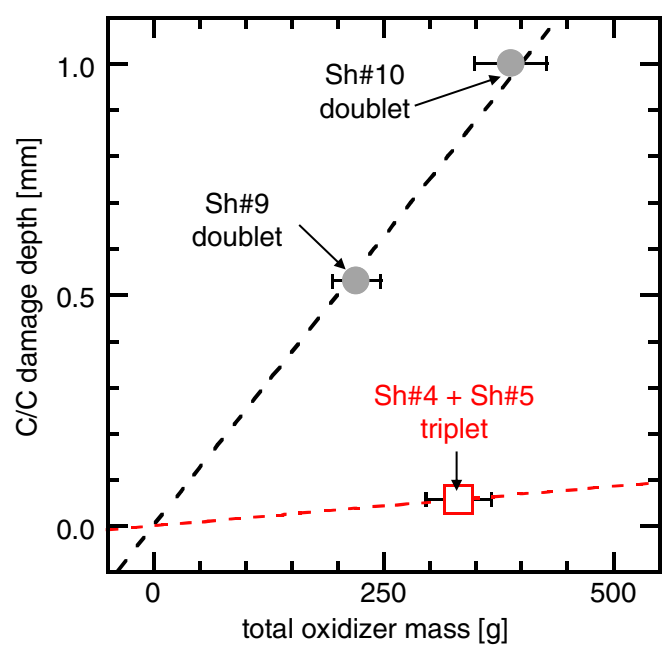

b) $\mathrm{C} / \mathrm{C}$ damage vs oxidizer mass

Fig. 13 Damage comparison of $\mathrm{C} / \mathrm{C}$ wall with doublet and triplet injection: a) photographs of $\mathrm{C} / \mathrm{C}$ damage, and b) $\mathrm{C} / \mathrm{C}$ damage vs oxidizer mass.

be necessary to determine accurate local heat transfer. Overall, the trend implied that wall heat flux should be roughly proportional to channel mass flux in the RDE. However, the general trend of bulk heat flux could be applicable to the primitive thermal design of RDE based on conventional heat transfer analysis.

\section{Wall Compatibility and Injector Design}

We next discuss $\mathrm{C} / \mathrm{C}$ composite wall compatibility and injector design. We conducted several combustion tests of up to $10 \mathrm{~s}$ with the $\mathrm{C} / \mathrm{C}$ composite wall $\mathrm{RDE}$ and compared the damage caused by oxidization. Ishihara et al. [29] hypothesized that $\mathrm{C} / \mathrm{C}$ damage would happen when the momentum of injected gas was not balanced. Therefore, we expected triplet injection to be better than doublet because it can create a low $\mathrm{O}_{2}$ environment nearby the combustor wall. The total amount of $\mathrm{C} / \mathrm{C}$ composite that can potentially react with oxygen should be proportional to total oxygen mass. Thus, we needed to define total oxygen mass consumed for $\mathrm{C} / \mathrm{C}$ oxidization. Carbon is known to react rapidly at temperatures as low as $773 \mathrm{~K}$ [34], and so we assumed that oxygen entering the RDE channel began to react when the wall temperature (technically $T_{z 9}$ or $T_{z 10}$ here) was above $800 \mathrm{~K}$. Therefore, we defined total consumed oxygen mass for $\mathrm{C} / \mathrm{C}$ oxidization as a product of oxygen mass flow rate and duration between the timing when wall temperatures exceeded $800 \mathrm{~K}$ and the end of combustion. Experimental conditions for this discussion are listed in Table 4. Thermocouple responses and the definition of oxygen consuming time mentioned previously are shown in Fig. 12.

$\mathrm{C} / \mathrm{C}$ walls were replaced after each test except for sh\#4 and sh $\overline{\# 5}$. We did not see clear C/C damage after the combustion test with the triplet injector, and so we continued to use the wall for sh\#4 and sh\#5. The comparison of injector design effect on $\mathrm{C} / \mathrm{C}$ composite damage is shown in Fig. 13. As expected, the triplet injector reduced the $\mathrm{C} / \mathrm{C}$ damage to less than $1 / 14$ that of the doublet design.

\section{Conclusions}

Thrust measurements of RDE with various throat geometries were conducted in a vacuum chamber to simulate different backpressure conditions ranging from 1.1-104 kPa. For throatless RDE, equivalent throat area was defined as the detonation channel area, and then three nozzle contraction ratios of $1,2.5$, and 8 were tested. The combustor pressure was measured, and it was reveled that it was almost proportional to the RDE throat mass flux. Thrust and specific impulse were measured for a wide range of ratios of the combustor pressure to the backpressure of the vacuum chamber (from 1.28 to 515). The RDE could achieve almost the same level of optimum specific impulse calculated from constant-pressure combustion at each backpressure, regardless of whether or not flow was squeezed by a geometric throat.

In addition, we measured bulk heat flux in the entire RDE by the difference method based on 1-D heat transfer analysis and the calorimetric method. Results revealed that the heat flux in an RDE was roughly proportional to channel mass flux, regardless of throat geometries. We demonstrated that a triplet injector had better wall compatibility of heat-resistant material compared to doublet injection.

\section{Acknowledgments}

The test piece and test chamber were manufactured by YasudaKoki Co., Ltd; Mizutani-Seiki Co., Ltd; Nakamura-Construction Co., Ltd; and Mashinax Co., Ltd. We would like to express our gratitude to other researchers who contributed to this study: Yuichi Kato, Kazuki Ishihara, Junichi Higashi, Haruna Taki, Takato Ukai, Yuki Hayamizu, Koyo Kikuchi, Taihei Yamada, Shun Watanabe, Koutaro Hotta, Tomoya Inakawa, Akiya Kubota, Masato Yamaguchi, and Toshiki Daicho at Nagoya University, as well as Kazuki Yasuda, Kenta Mori, and Hiromitsu Yagihashi at Muroran Institute of Technology. RDE development was subsidized by a "Study on Innovative Detonation Propulsion Mechanism," Researchand-Development Grant Program (Engineering) from the Institute of Space and Astronautical Science (Japan Aerospace Exploration Agency), and a "Research and Development of an Ultra-HighThermal-Efficiency Rotating Detonation Engine with SelfCompression Mechanism," Advanced Research Program for Energy and Environmental Technologies (New Energy and Industrial Technology Development Organization). The fundamental device development was subsidized by Grants-in-Aid for Scientific Research 24246137 and $17 \mathrm{H} 03480$.

\section{References}

[1] Kailasanath, K., "Review of Propulsive Applications of Detonation Waves," AIAA Journal, Vol. 38, No. 9, 2000, pp. 1698-1708. doi: $10.2514 / 2.1156$

[2] Kailasanath, K., "Recent Developments in the Research on Pulse Detonation Engines," AIAA Journal, Vol. 41, No. 2, 2003, pp. 145-159. doi: $10.2514 / 2.1933$

[3] Wolanski, P., "Detonative Propulsion," Proceedings of the Combustion Institute, Vol. 34, No. 1, 2013, pp. 125-158. doi:10.1016/j.proci.2012.10.005

[4] Li, J. M., Teo, C. J., Khoo, B. C., Yao, S., and Wang, C., (eds.), Detonation Control for Propulsion Pulse Detonation and Rotating Detonation Engines, Springer, Cham, Switzerland, 2018. doi:10.1007/978-3-319-68906-7 
[5] Lu, F. K., and Braun, E. M., "Rotating Detonation Wave Propulsion: Experimental Challenges, Modeling, and Engine Concepts," Journal of Propulsion and Power, Vol. 30, No. 5, 2014, pp. 1125-1142. doi:10.2514/1.B34802

[6] Kasahara, J., Hasegawa, A., Nemoto, T., Yamaguchi, H., Yajima, T., and Kojima, T., "Performance Validation of a Single-Tube Pulse Detonation Rocket System," Journal of Propulsion and Power, Vol. 25, No. 1, 2009, pp. $173-180$ doi:10.2514/1.37924

[7] Matsuoka, K., Morozumi, T., Takagi, S., Kasahara, J., Matsuo, A., and Funaki, I., "Flight Validation of a Rotary-Valved Four-Cylinder Pulse Detonation Rocket," Journal of Propulsion and Power, Vol. 32, No. 2, 2016, pp. 383-391. doi:10.2514/1.B35739

[8] Frolov, S. M., Aksenov, V. S., Gusev, P. A., Ivanov, V. S., Medvedev, S. N., and Shamshin, I. O., "Experimental Proof of the Energy Efficiency of the Zel'dovich Thermodynamic Cycle," Doklady Physical Chemistry, Vol. 459, No. 2, 2014, pp. 207-211. doi:10.1134/S0012501614120057

[9] Bykovskii, F. A., Zhdan, S. A., and Vedemikov, E. F., "Continuous Spin Detonations," Journal of Propulsion and Power, Vol. 22, No. 6, 2006, pp. 1204-1216. doi:10.2514/1.17656

[10] George, A. S., Driscoll, R., Anand, V., and Gutmark, E., "On the Existence and Multiplicity of Rotating Detonations," Proceedings of the Combustion Institute, Vol. 36, No. 2, 2017, pp. 2691-2698. doi:10.1016/j.proci.2016.06.132

[11] Nakayama, H., Moriya, T., Kasahara, J., Matsuo, A., Sasamoto, Y., and Funaki, I., "Stable Detonation Wave Propagation in Rectangular-CrossSection Curved Channels," Combustion and Flame, Vol. 159, No. 2, 2012, pp. 859-869. doi:10.1016/j.combustflame.2011.07.022

[12] Kindracki, J., Wolanski, P., and Gut, Z., "Experimental Research on the Rotating Detonation in Gaseous Fuel-Oxygen Mixtures," Shock Waves, Vol. 21, No. 2, 2011, pp. 75-84. doi:10.1007/s00193-011-0298-y

[13] Yi, T. H., Lou, J., and Turangan, C., "Propulsive Performance of a Continuously Rotating Detonation Engine," Journal of Propulsion and Power, Vol. 27, No. 1, 2011, pp. 171-181. doi: $10.2514 / 1.46686$

[14] Wu, D., Zhou, R., Liu, M., and Wang, J., "Numerical Investigation of the Stability of Rotating Detonation Engines," Combustion Science and Technology, Vol. 186, Nos. 10-11, 2014, pp. 1699-1715. doi:10.1080/00102202.2014.935641

[15] Yao, S., Tang, X., Luan, M., and Wang, J., "Numerical Study of Hollow Rotating Detonation Engine with Different Fuel Injection Area Ratios," Proceeding of the Combustion Institute, Vol. 36, No. 2, 2017, pp. 2649-2655. doi:10.1016/j.proci.2016.07.126

[16] Kawasaki, A., Inakawa, T., Kasahara, J., Goto, K., Matsuoka, K., Matsuo, A., and Funaki, I., "Critical Condition of Inner Cylinder Radius for Sustaining Rotating Detonation Waves in Rotating Detonation Engine Thruster," Proceedings of the Combustion Institute, (to be published).

[17] Mizener, A. R., and Lu, F. K., "Low-Order Parametric Analysis of a Rotating Detonation Engine in Rocket Mode," Journal of Propulsion and Power, Vol. 33, No. 6, 2017, pp. 1543-1554. doi:10.2514/1.B36432

[18] Schwer, D., and Kailasanath, K., "Numerical Investigation of the Physics of Rotating-Detonation-Engines," Proceedings of the Combustion Institute, Vol. 33, No. 2, 2011, pp. 2195-2202. doi:10.1016/j.proci.2010.07.050

[19] Kasahara, J., Kato, Y., Ishihara, K., Goto, K., Matsuoka, K., Matsuo, A., Funaki, I., Moriai, H., Nakata, D., Higashino, K., and Tanatsugu, N., Application of Detonation Waves to Rocket Engine Chamber," Detonation Control for Propulsion Pulse Detonation and Rotating Detonation Engines, edited by J. M. Li, C. J. Teo, B. C. Khoo, S. Yao, and C. Wang, Springer, Cham, Switzerland, 2018. doi:10.1007/978-3-319-68906-7_4

[20] Frolov, S. M., Aksenov, V. S., Ivanov, V. S., and Shamshin, I. O., "Large-Scale Hydrogen-Air Continuous Detonation Combustor," International Journal of Hydrogen Energy, Vol. 40, No. 3, 2015, pp. 1616-1623.

doi:10.1016/j.ijhydene.2014.11.112

[21] Rankin, B. A., Kaemming, T. A., Theuerkauf, S. W., and Schauer, F. R., "Overview of Performance, Application, and Analysis of Rotating Detonation Engine Technologies," Journal of Propulsion and Power, Vol. 33, No. 1, 2017, pp. 131-143. doi:10.2514/1.B36303

[22] Fotia, M. L., Schauer, F., Kaemming, T., and Hoke, J., "Experimental Study of the Performance of a Rotating Detonation Engine with Nozzle," Journal of Propulsion and Power, Vol. 32, No. 3, 2016, pp. 674-681. doi:10.2514/1.B35913

[23] Fotia, M. L., Hoke, J., and Schauer, F., "Experimental Performance of Rotating Detonation Engines Operated on Gaseous Fuels," Journal of Propulsion and Power, Vol. 33, No. 5, 2017, pp. 1187-1196. doi:10.2514/1.B36213

[24] Theuerkauf, S. W., Schauer, F. R., and Anthony, R., "Experimental Characterization of High-Frequency Heat Flux in a Rotating Detonation Engine," 53th AIAA Aerospace Science Meeting, AIAA Paper 2015-1603, Jan. 2015 doi:10.2514/6.2015-1603

[25] Bykovskii, F. A., "Thermal Fluxes in Combustion Chamber Walls in the Detonation and Turbulent Combustion Modes," Combustion, Explosion, and Shock Waves, Vol. 27, No. 1, 1991, pp. 66-71. doi:10.1007/BF00785359

[26] Bykovskii, F. A., and Vedernikov, E. F., "Heat Fluxes to Combustor Walls During Continuous Spin Detonation of Fuel-Air Mixtures," Combustion, Explosion, and Shock Waves, Vol. 45, No. 1, 2009, pp. 70-77. doi:10.1007/s10573-009-0010-z

[27] Braun, J., Sousa, J., and Paniagua, G., "Numerical Assessment of the Convective Heat Transfer in Rotating Detonation Combustors Using a Reduced-Order Model," Applied Science, Vol. 8, No. 6, 2018, p. 893. doi:10.3390/app8060893

[28] Stevens, C. A., Fotia, M. L., and Hoke, J. L., "Quasi-Steady Heat Transfer Measurements in an RDE," 2018 AIAA Aerospace Science Meeting, AIAA Paper 2018-1884, Jan. 2018. doi:10.2514/6.2018-1884

[29] Ishihara, K., Nishimura, J., Goto, K., Nakagami, S., Matsuoka, K., Kasahara, J., Matsuo, A., Funaki, I., Moriai, H., Mukae, H., Yasuda, K., Nakata, D., and Higashino, K., "Study on a Long-Time Operation Towards Rotating Detonation Rocket Engine Flight Demonstration," 55th AIAA Aerospace Sciences Meeting, AIAA Paper 2017-1062, Jan. 2017. doi: $10.2514 / 6.2017-1062$

[30] Goto, K., Nishimura, J., Higashi, J., Taki, H., Ukai, T., Hayamizu, Y., Kikuchi, K., Yamada, T., Watanabe, S., Hotta, K., Inakawa, I., Kubota, A., Yamaguchi, M., Daicho, T., Kawasaki, A., Matsuoka, K., Kasahara, J., Matsuo, A., Funaki, I., Yasuda, K., Mori, K., Yagihashi, H., Nakata, D., Masaharu, U., and Higashino, K., "Preliminary Experiments on Rotating Detonation Rocket Engine for Flight Demonstration Using Sounding Rocket," 2018 AIAA Aerospace Science Meeting, AIAA Paper 2018-0157, 2018. doi: $10.2514 / 6.2018-0157$

[31] Gordon, S., and McBride, B. J., "Computer Program for Calculation of Complex Chemical Equilibrium Compositions and Applications," NASA RP-1311, 1996.

[32] Dittus, F., and Boelter, M., Heat Transfer in Automobile Radiators of the Tubular Type, Publications in Engineering, Univ. of California, Berkeley, CA, Vol. 2, 1930, p. 443.

[33] Huzel, D. K., and Huang, D. H., Modern Engineering for Design of Liquid-Propellant Rocket Engines, Progress in Astronautics, Vol. 147, AIAA, Washington, DC, 1992, p. 86.

[34] Bacos, M., "Carbon-Carbon Composites: Oxidation Behavior and Coatings Protection," Journal de Physique IV Colloque, Vol. 3, No. C7, 1993, pp. 1895-1903. doi:10.1051/jp4:19937303

V. Raman

Associate Editor 